\title{
Prática pedagógica e docência: o olhar do professor de educação física no enfrentamento da
} Covid-19

\author{
Pedagogical practice and teaching: the view of the physical education teacher facing Covid-19 \\ Práctica y enseñanza pedagógica: la visión del profesor de educación física en el enfrentamiento \\ con Covid-19
}

\author{
Rogério Zaim-de-Melo', Deyvid Tenner de Souza Rizzo ${ }^{\mathrm{II}}$, Edineia Aparecida Gomes Ribeiro ${ }^{\mathrm{III}}$
}

\begin{abstract}
Resumo
Este artigo apresenta a prática pedagógica da educação física, durante período de isolamento imposto pela pandemia de Covid-19, a partir da percepção docente. A pesquisa qualitativa foi realizada com 69 professores de educação física do estado do Mato Grosso do Sul, Brasil, atuantes na educação básica durante a pandemia. Para construção dos dados foi aplicado um questionário on-line com informações sobre a compreensão da prática pedagógica desses professores. Os dados apontaram experiências positivas com as novas práticas pedagógicas adotadas no período de isolamento, contudo, uma classe de professores aponta que enfrenta dificuldades e não acredita nas adaptações das aulas nessas condições. Considera-se que, à medida que a doença causada pelo novo coronavírus se espalha pelo mundo, e ameaça o sistema econômico e social, gestores e educadores precisam se preparar para ensinar e apoiar os alunos diante de qualquer dificuldade apresentada, dispondo-se a enfrentar os possíveis e significativos impactos de longo prazo na educação.
\end{abstract}

Palavras-chave: Educação Física; Educação; Pandemia

\begin{abstract}
This research was carried out with 69 Physical Education (PE) teachers from Mato Grosso do Sul state, Brazil, who worked in Basic Education during the Covid-19 pandemic. It aims to understand the pedagogical practice of the PE curricular component during the isolation period imposed by the pandemic from the teacher's point of view. The research is of a qualitative nature and used an online questionnaire that sought information to characterize the understanding of the pedagogical practice of PE teachers. The data showed positive experiences with the new pedagogical practices adopted during the isolation period, however, a class of teachers indicated that they faced difficulties and do not believe in the adaptations of the classes during Covid-19. It is considered that, as the disease caused by the new coronavirus spreads around the world, and threatens the economic and social systems, managers and educators need to focus on one action: prepare to teach and support students in the face of any difficulties presented and be available to address the possible and significant long-term impacts on education.
\end{abstract}

Keywords: Physical Education; Education; Pandemic

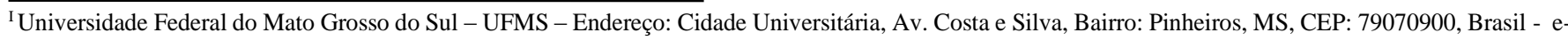
mail: rogeriozmelo@gmail.com

II Universidade Federal do Mato Grosso do Sul - UFMS - e-mail: deyvidrizzo1@ gmail.com

${ }^{\text {III }}$ Universidade Federal do Mato Grosso do Sul - UFMS - e-mail: edineia.ag.ribeiro@ufms.br
} 


\section{Resumen}

Este artículo presenta la práctica pedagógica de la educación física durante período de aislamiento impuesto por la pandemia de la Covid-19, a partir de la percepción de los docentes. La investigación cualitativa se llevó a cabo con 69 profesores de educación física de la provincia del Mato Grosso do Sul, Brasil, que trabajan en la educación primaria durante la pandemia. Para la construcción de datos se aplicó un cuestionario en línea con informaciones sobre la comprensión de la práctica pedagógica de estos docentes. Los datos indican experiencias positivas con las nuevas prácticas pedagógicas adoptadas durante el período de aislamiento, sin embargo, un grupo de docentes señala que enfrentan dificultades y no creen en las adaptaciones de las clases en estas condiciones. Se considera que, a medida que la enfermedad provocada por el nuevo coronavirus se propaga por el mundo y amenaza el sistema económico y social, los gestores y educadores deben prepararse para enseñar y apoyar a los estudiantes ante cualquier dificultad que se presente, dispuestos a afrontar los posibles y significativos impactos a largo plazo en la educación.

Palabras clave: Educación Física; Educación; Pandemia

\section{Introdução}

Na transição do ano de 2019 para 2020, a Covid-19, causada pelo novo coronavírus SARS-CoV-2, foi identificada pelo Centro de Controle e Prevenção de Doenças na China (CHEN et al, 2020). Segundo o Ministério da Saúde (2020), esse vírus causa infecções respiratórias e apresenta como sintomas: tosse, febre, coriza, dor de garganta e dificuldades para respirar. Em suma, a transmissão acontece de uma pessoa doente para outra ou por contato próximo. As recomendações de prevenção à Covid-19 são diversas, incluindo o isolamento social.

Em janeiro de 2020, a Organização Mundial da Saúde (OMS) declarou o surto dessa doença como Emergência de Saúde Pública de Importância Internacional e, em de março de 2020, caracterizou esta como uma pandemia (WHO, 2020). No Brasil, após o registro do primeiro caso, as autoridades sanitárias locais em diferentes esferas administrativas (federal, estaduais e municipais) tentaram aplicar medidas de controle e prevenção da doença. Apesar de estas terem sido diferenciadas entre as diferentes regiões do país, a medida mais difundida pelas autoridades foi a prática do distanciamento social (PIRES, 2020), entendida pela população e pela mídia - como isolamento social (FARIAS, 2020).

No quesito educacional, as atividades presenciais nas escolas municipais, estaduais, federais e privadas de Mato Grosso do Sul foram suspensas. Em um primeiro momento, acreditando-se em uma quarentena rápida, nenhuma ação foi tomada de imediato. Com o agravamento da situação, as escolas começaram a trabalhar com atividades a distância, de forma remota, procurando seguir com o calendário normal, com novos conteúdos e avaliações tendo que ser flexibilizados.

Essas decisões produziram uma situação drástica na educação brasileira e internacional, sem nenhum preparo. De repente, o sistema educacional começou a funcionar sem a presença de alunos e 
professores na escola. Uma situação que, inclusive, entrará nos debates sobre formação do professor de educação física (SANTOS; PAULA; STIEG, 2019).

Nesse contexto, tanto escolas (coordenação, professores e alunos) como familiares e responsáveis precisaram fazer um grande esforço para manter o processo ensino e aprendizagem. Os professores, em alguns casos, com auxílio dos coordenadores, tiveram que (em tempo recorde) adequar os conteúdos que seriam ministrados presencialmente e as metodologias que deveriam ser aplicadas com seus alunos em quarentena. A isso foram, somadas as incertezas com prazos, a falta de treinamento com as ferramentas digitais e a falta de acesso à internet pelos alunos. Dessa forma, pais e responsáveis tiveram que se comprometer com novas demandas da escola e adequação do ensino, principalmente na rede pública.

A urgência para que, já nas primeiras semanas, os professores, agora assumido tarefas a partir de suas casas, realizassem a transposição de seus planejamentos para plataformas virtuais e recursos pela internet conduz à reprodução pura e simples da exposição oral presencial para a repetição à distância das explicações e exercícios. (SANTANA FILHO, 2020, p. 6).

Diante das mudanças didático-pedagógicas solicitadas para o enfrentamento da Covid-19, o professor de educação física precisou se reinventar, adaptar suas aulas, principalmente aquelas que o conteúdo requeria atividades eminentemente práticas, buscando também o domínio de recursos tecnológicos, bem como sua aplicação junto aos alunos, tornando os desafios pedagógicos mais recorrentes em tempos de pandemia.

Dessa forma, o presente estudo busca conhecer como essas ações estão sendo realizadas entre os professores de educação física, uma vez que existem carências de estudos sobre a temática. Assim, o objetivo do estudo é compreender a prática pedagógica da Educação Física, enquanto componente curricular obrigatório da Educação Básica, durante período de isolamento imposto pela pandemia do Covid19.

As significações atribuídas para a prática pedagógica e docência são, a todo o momento, possibilidades de legitimação para abertura de novos debates nas circunstâncias que transcendem a escola, nomeadamente na educação física escolar. É comum assegurar que práticas pedagógicas se referem à concretização de quaisquer processos educacionais de modo amplo, difuso e aleatório. Ora, a princípio, o que é uma prática pedagógica? Essa pergunta é muito comum no meio acadêmico, principalmente entre alunos e professores. Longe de reducionismos, sustentamos a presente discussão na definição de prática pedagógica definida por Franco (2016), ao advogar que, em seu sentido de práxis, configura-se sempre como uma ação consciente e participativa, a qual surge da multidimensionalidade do ato educativo. Contudo, destaca-se que o conceito de prática pedagógica poderá variar, dependendo da compreensão de pedagogia e, até mesmo, do sentido que se atribui à prática (FRANCO, 2016). 
Como componente curricular, a educação física tem como objetivo ampliar o conhecimento sobre as práticas corporais (BATISTA; MOURA, 2019), portanto, destacamos que a docência pode ser uma resposta das ações provenientes da prática pedagógica. Contudo, o debate sobre práticas pedagógicas no campo de ensino da educação física escolar ainda é escasso na literatura brasileira, o número reduzido de produções existentes dilui-se em diferentes matrizes teóricas, o que dificulta as discussões sobre essa temática.

São encontrados estudos com investigações envolvendo princípios que fundamentam a prática pedagógica docente na educação física, predominantemente não diretiva (OLIVEIRA; DAOLIO, 2014) ou com orientações para a organização de práticas pedagógicas como componente curricular direcionado para inclusão social e esporte na educação física escolar (CARLAN; KUNZ; FENSTERSEIFER, 2012; CASSANI et al, 2019; MILISTETD et al, 2017). A partir de reflexões e propostas de metodologias ativas (MOTA; ROSA, 2018) que visam reconfigurar e avaliar a ação docente, os modos de intervenção crítica da realidade educacional (SILVA, 2019). Todavia, a falta de consenso é uma das principais dificuldades envolvendo a problemática.

Acreditamos que a prática pedagógica do professor de educação física deve se sustentar ontologicamente e questionar frequentemente as condições e possibilidades de determinados fluxos de conhecimento desenvolvidos por meio do conteúdo no contexto do currículo escolar. "Essa perspectiva curricular prestigia, desde seu planejamento, estratégias democráticas para a definição dos conteúdos e atividades de ensino" (CASTRO NETA et al, 2020, p. 5). Destarte, questionamos: quais as marcas de uma prática pedagógica orientada pela docência em educação física, em período de isolamento social, durante a pandemia da Covid-19?

\section{Metodologia}

Para atingir os objetivos da pesquisa, foi realizado um estudo qualitativo de cunho exploratório, "um estudo do status" (THOMAS; NELSON; SILVERMAN, 2012, p. 293). Nesse tocante, o status da compreensão da prática pedagógica do componente curricular educação física durante o período de isolamento imposto pela pandemia de Covid-19.

Optamos por uma abordagem de natureza qualitativa, indicada para investigar problemas que apenas os procedimentos estatísticos não podem alcançar ou representar, em virtude de sua complexidade (LIMENA; RODRIGUES, 2006). Entre esses problemas, destacam-se aspectos sociais, psicológicos, opiniões, comportamentos, atitudes de indivíduos ou de grupos. Consideramos, de acordo com Minayo 
(2004, p. 35), que "nada pode ser intelectualmente um problema, se não tiver sido, em primeiro lugar, um problema da vida prática".

Para atingir os propósitos deste estudo, optamos por uma amostragem não probabilística, do tipo snowball sampling (HANDCOCK; GILE, 2011), na qual os primeiros sujeitos que aceitam participar do estudo vão fornecendo o contato de outros e, em alguns casos, convidando seus pares a participarem. Também, utilizamos as mídias sociais e listas de egressos da universidade, para que pudéssemos encontrar os participantes da pesquisa. A opção por essa técnica deu-se por ser recomendada para se alcançar populações de difícil acesso, a ideia foi conseguirmos participantes de diversos municípios do estado de Mato Grosso do Sul (MS).

A população investigada foi composta por professores de educação física do Mato Grosso do Sul, que atuaram na educação básica durante um período de isolamento imposto pela pandemia de Covid-19. Todos os sujeitos enquadrados nos critérios supracitados consentiram em participar da pesquisa, resultando em uma amostra composta por 100\% dos indivíduos da população-alvo. A amostra de sujeitos investigados foi constituída por 69 professores de educação física (38 do sexo feminino e 31 do masculino), com idades de 21 a 49 anos, residentes em várias cidades do estado de Mato Grosso do Sul, como evidencia o Quadro 1. :

Quadro 1: Quadro geral de participantes

\begin{tabular}{|l|c|}
\hline \multicolumn{1}{|c|}{ Cidades } & $\mathbf{N}^{\mathbf{0}}$ de participantes \\
\hline Amambai & 5 \\
\hline Antônio João & 4 \\
\hline Aquidauana & 5 \\
\hline Batayporã & 3 \\
\hline Campo Grande & 8 \\
\hline Coronel Sapucaia & 5 \\
\hline Corumbá & 5 \\
\hline Dourados & 9 \\
\hline Indápolis & 3 \\
\hline Glória de Dourados & 2 \\
\hline Guia Lopes da Laguna & 2 \\
\hline Ladário & 4 \\
\hline Maracaju & 1 \\
\hline Nova Andradina & 5 \\
\hline Ponta Porã & 6 \\
\hline
\end{tabular}

Fonte: Elaboração própria. 
Para coleta de dados, no período de maio a junho de 2020, utilizamos um questionário on-line, elaborado com auxílio de uma ferramenta para a criação de formulários do Google Forms. O instrumento, composto por 20 questões (abertas e de múltipla escolha), buscou reunir informações que caracterizam a compreensão da prática pedagógica dos sujeitos da pesquisa em relação ao componente curricular educação física, durante período de isolamento imposto pela pandemia de Covid-19. O link do questionário foi socializado em redes sociais e enviado na lista de e-mail dos egressos cadastrados no sistema interno da universidade proponente dos pesquisadores.

As questões versavam sobre o conteúdo trabalhado durante o período da pesquisa, os recursos pedagógicos utilizados pelos professores, e aqueles que tinham acesso, se houve apoio da escola para que as atividades propostas pudessem ser desenvolvidas.

\section{Resultados}

Em suma, as questões apresentadas a seguir interrogaram os professores sobre as percepções de docência e as práticas pedagógicas adotadas na educação física escolar em período de isolamento social durante a pandemia de Covid-19. Os professores atuam predominante na rede pública municipal (38), os demais estão divididos na esfera estadual (13), federal (3) e privada (15), com carga horária concentrada nas seguintes etapas de ensino: educação infantil (15), ensino fundamental - séries iniciais (15), ensino fundamental - séries finais (23), ensino médio (16).

Sobre a titulação acadêmica, 35 professores possuem Especialização (pós-graduações lato sensu) em alguma área da educação física; 9 professores são mestres; dois doutores; e 23 são licenciados em Educação Física.

Quando questionados sobre qual(is) o(s) conteúdo(s) do currículo escolar que desenvolviam durante esse período de isolamento social, as respostas indicaram ampla heterogeneidade. Utilizando a classificação presente na BNCC, os conteúdos abordados são os apresentados na sequência.

- Brincadeiras e jogos: jogos e brincadeiras, atividades lúdicas e interacionais, brincadeiras populares regionais e mundiais, atividade lúdicas, confecção de brinquedos.

- Esportes: contexto histórico dos esportes coletivos, esportes de invasão, evolução das práticas esportivas, esporte de precisão (tiro ao alvo).

- Ginásticas: ginástica geral.

- Danças: atividades rítmicas, dança, gestos e movimento. 
- Lutas: lutas.

- Práticas corporais de aventura: esportes de aventura.

Os conteúdos expressos na fala dos professores que não se enquadram na classificação, mas que podem ser trabalhados em qualquer um deles, são: coordenação motora, alimentação saudável, higiene pessoal, educação física adaptada, capacidades físicas, corpo humano, habilidades motoras básicas, socorros de urgência e emergência; importância da atividade física, exercício físico, sedentarismo, condicionamento físico, saúde e bem-estar.

Ainda, foram citados pelos professores: medidas de prevenção à Covid-19 (lavar mãos, usar máscara e álcool em gel) e dois professores não especificaram o que estavam trabalhando.

O Quadro 2 aponta qual o recurso pedagógico utilizado com mais frequência pelos professores enquanto os alunos não puderam ir à escola no período.:

Quadro 2: Recursos tecnológicos utilizados pelos professores de educação física do MS durante pandemia do Covid 19

\begin{tabular}{|l|c|}
\hline \multicolumn{1}{|c|}{ Recurso pedagógico } & Percentual (\%) \\
\hline Redes sociais & 31,9 \\
\hline Vídeos em plataformas digitais & 26,1 \\
\hline Plataforma/ recursos de ensino a distância & 18,8 \\
\hline Textos impressos & 8,7 \\
\hline Sites on-line & 8,7 \\
\hline Grupos de salas do WhatsApp & 1,4 \\
\hline Videochamadas & 1,4 \\
\hline Videoaulas e videoconferências & 1,4 \\
\hline $\begin{array}{l}\text { Slides no Power Point com explicação de } \\
\text { conteúdos por áudio }\end{array}$ & 1,4 \\
\hline Programas educativos pela televisão & 0 \\
\hline
\end{tabular}

Fonte: Elaboração própria.

Em geral, a maioria dos professores ressaltou que as equipes técnico-pedagógicas das escolas em que atuam apoiam a continuidade da experiência didático-pedagógica durante período de isolamento social: "Disponibilizou plataforma e capacitação dos professores para aprender a usar as ferramentas digitais" disse o Professor 16 (PR 16); “Auxilia com conteúdo impresso aos alunos que não possuem acesso à internet" (PR 43); "Instruiu quais recursos utilizar e como desenvolver as atividades, além de acompanhar" (PR 52); "Fez grupos para ser divulgado aos pais as aulas" (PR 61).

Contudo, um pequeno grupo de professores destacou uma situação diferente, na qual a escola dificulta as ações referentes ao isolamento social: “Ameaçou de dispensar quem não cumprisse com o 
proposto (um grande incentivo)" (PR 25); "Nada, pois julgam que a educação física não seja tão importante como português e matemática" (PR 46).

Os professores ainda descreveram os principais aprendizados que estão adquirindo nessa experiência de educação remota durante a pandemia. Ao categorizar as respostas dos professores, visualizam-se aproximações e distanciamentos nos discursos, descritos em duas classes.

A primeira classe indica evidências de que os professores tiveram experiências positivas com as novas práticas pedagógicas adotadas em período de isolamento. A segunda classe aponta como eles enfrentam dificuldades e não acreditam nas adaptações das aulas durante a pandemia, conforme indicam seus depoimentos:

Quadro 3: Experiência docente durante o enfrentamento contra a Covid-19

\begin{tabular}{|c|c|c|c|}
\hline \multicolumn{2}{|r|}{ Experiências positivas } & \multicolumn{2}{|r|}{ Experiências contrárias } \\
\hline PR 17 & $\begin{array}{l}\text { A educação física na era digital pode } \\
\text { funcionar. }\end{array}$ & PR 26 & $\begin{array}{l}\text { Só se comprovou que educação a } \\
\text { distância, para a rede pública } \\
\text { (principalmente no fundamental), } \\
\text { não funciona. }\end{array}$ \\
\hline PR 19 & $\begin{array}{l}\text { Olhar sistemático sobre as realidades em } \\
\text { se desenvolver uma metodologia } \\
\text { melhor, para que os conteúdos cheguem } \\
\text { para os alunos. }\end{array}$ & PR 10 & $\begin{array}{l}\text { Nenhum tipo de tecnologia vai } \\
\text { substituir um professor presencial. }\end{array}$ \\
\hline PR 02 & $\begin{array}{l}\text { Descoberta de novas maneiras de } \\
\text { transmitir conhecimento. }\end{array}$ & PR 69 & $\begin{array}{l}\text { Só mostra que, de fato, a educação a } \\
\text { distância não funciona. Trabalho com } \\
\text { alunos muito pobres, a maioria vai pra } \\
\text { escola para comer. Então, como eles } \\
\text { terão acesso a qualquer mídia para } \\
\text { desenvolver a atividade proposta? }\end{array}$ \\
\hline PR 33 & Trabalhar por meio de meios digitais. & PR 55 & Odiei. \\
\hline PR 20 & Temos grande capacidade de adaptação & PR 31 & Nada que eu já não sabia. \\
\hline PR 05 & $\begin{array}{l}\text { Rever conceitos, diminuir o afeto, deixar } \\
\text { de se importar com coisas fúteis, } \\
\text { preocupar mais comigo e minha família. }\end{array}$ & PR 47 & Ela nem existe. \\
\hline
\end{tabular}

Fonte: Elaboração própria.

O Gráfico 1 representa o quantitativo de professores que tiveram que aprender a usar novas ferramentas tecnológicas durante o período de trabalho remoto: 
Gráfico 1: Você teve que aprender a usar novas ferramentas tecnológicas?

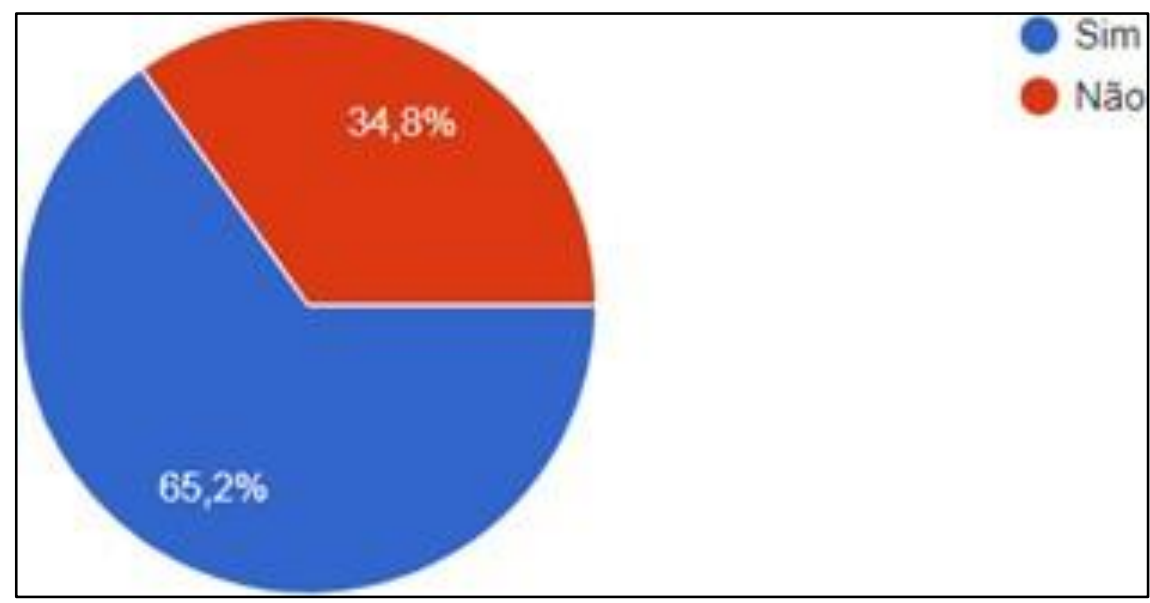

Fonte: Elaboração própria.

Os professores que responderam "sim" citaram as seguintes ferramentas: Google Classroom, Apps de edição de vídeos, Hangouts, Google Meet, Google Drive, Google Forms, Microsoft Teams, plataforma do Moodle, redes sociais, Google Play.

O quadro a seguir demonstra as principais dificuldades encontradas pelos professores para organização e desenvolvimento da prática pedagógica:

Quadro 4: Recursos pedagógicos

\begin{tabular}{|l|c|}
\hline \multicolumn{1}{|c|}{ Dificuldades } & Percentual (\%) \\
\hline $\begin{array}{l}\text { Desigualdade social enfrentada pelos estudantes - acesso } \\
\text { limitado à internet, falta de computadores e de espaço em } \\
\text { casa e baixa escolaridade dos familiares }\end{array}$ & 65,2 \\
\hline $\begin{array}{l}\text { Carência de formação para o uso das Tecnologias de } \\
\text { Informação e Comunicação (TICs) }\end{array}$ & 14,5 \\
\hline Ausência de orientação da gestão escolar & 8,7 \\
\hline $\begin{array}{l}\text { Dificuldade em identificar como estabelecer contato com } \\
\text { os alunos }\end{array}$ & 5,8 \\
\hline $\begin{array}{l}\text { Pouca motivação para ministrar o conteúdo de forma } \\
\text { remota }\end{array}$ & 1,4 \\
\hline Dificuldades de utilizar as ferramentas virtuais & 1,4 \\
\hline $\begin{array}{l}\text { Falta de motivação de alguns alunos para participar das } \\
\text { aulas }\end{array}$ & 1,4 \\
\hline Nenhuma & 1,4 \\
\hline
\end{tabular}

Fonte: Elaboração própria.

A respeito da docência na educação física escolar, quatro perguntas tentaram mensurar o grau da opinião dos professores, em uma escala de 1 a 5, em que $1=$ Nunca, $2=$ Raramente, $3=$ Às vezes, $4=$ Muitas Vezes e 5 = Sempre, e ilustra como eles têm conseguido desenvolver suas atividades docentes durante período de isolamento social. Vejamos os resultados no Quadro 5. 
Quadro 5: Opiniões dos professores acerca das aulas práticas durante a pandemia

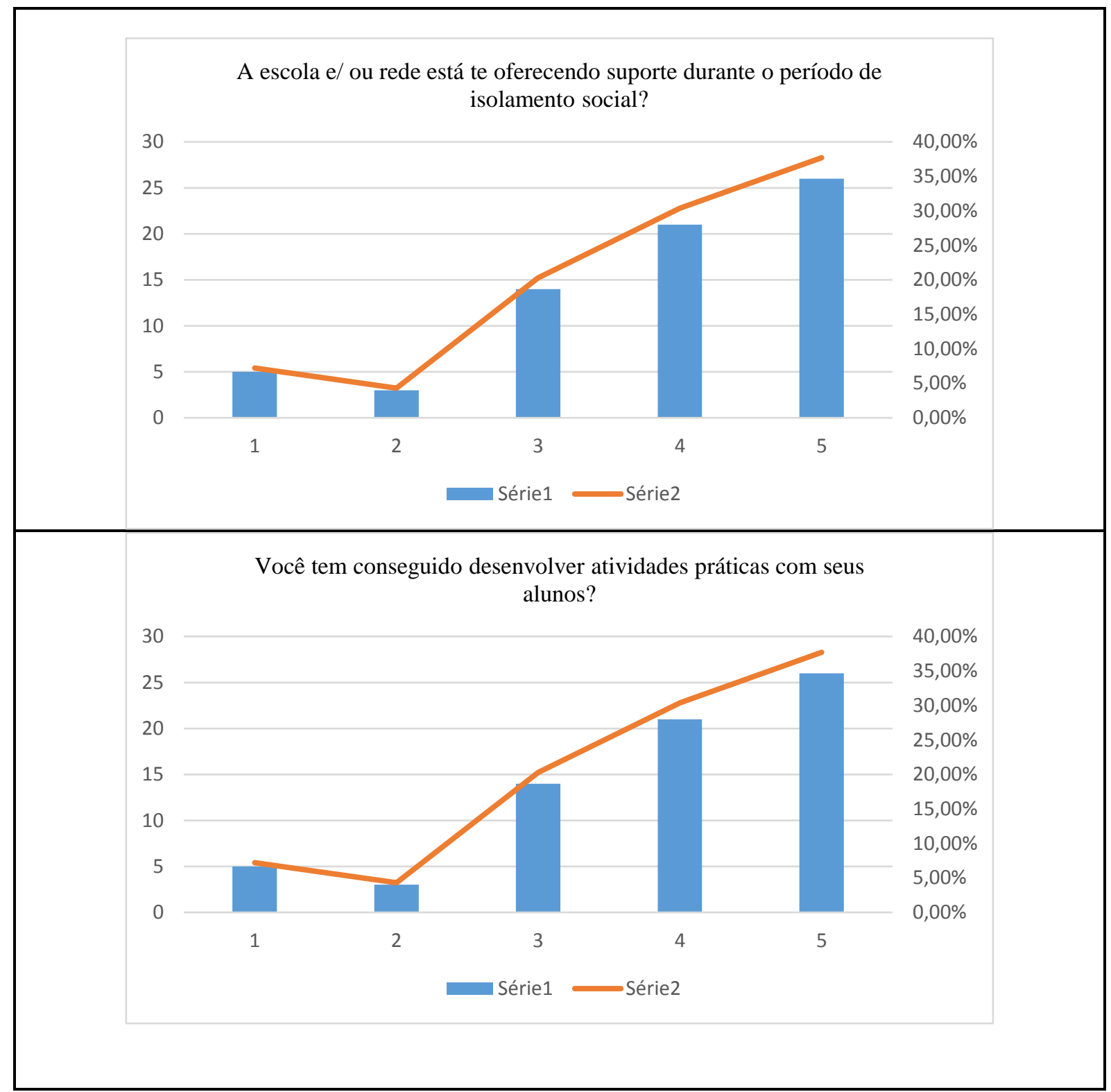

Revista Kinesis, Santa Maria, v. 39, p.01-17, 2021 


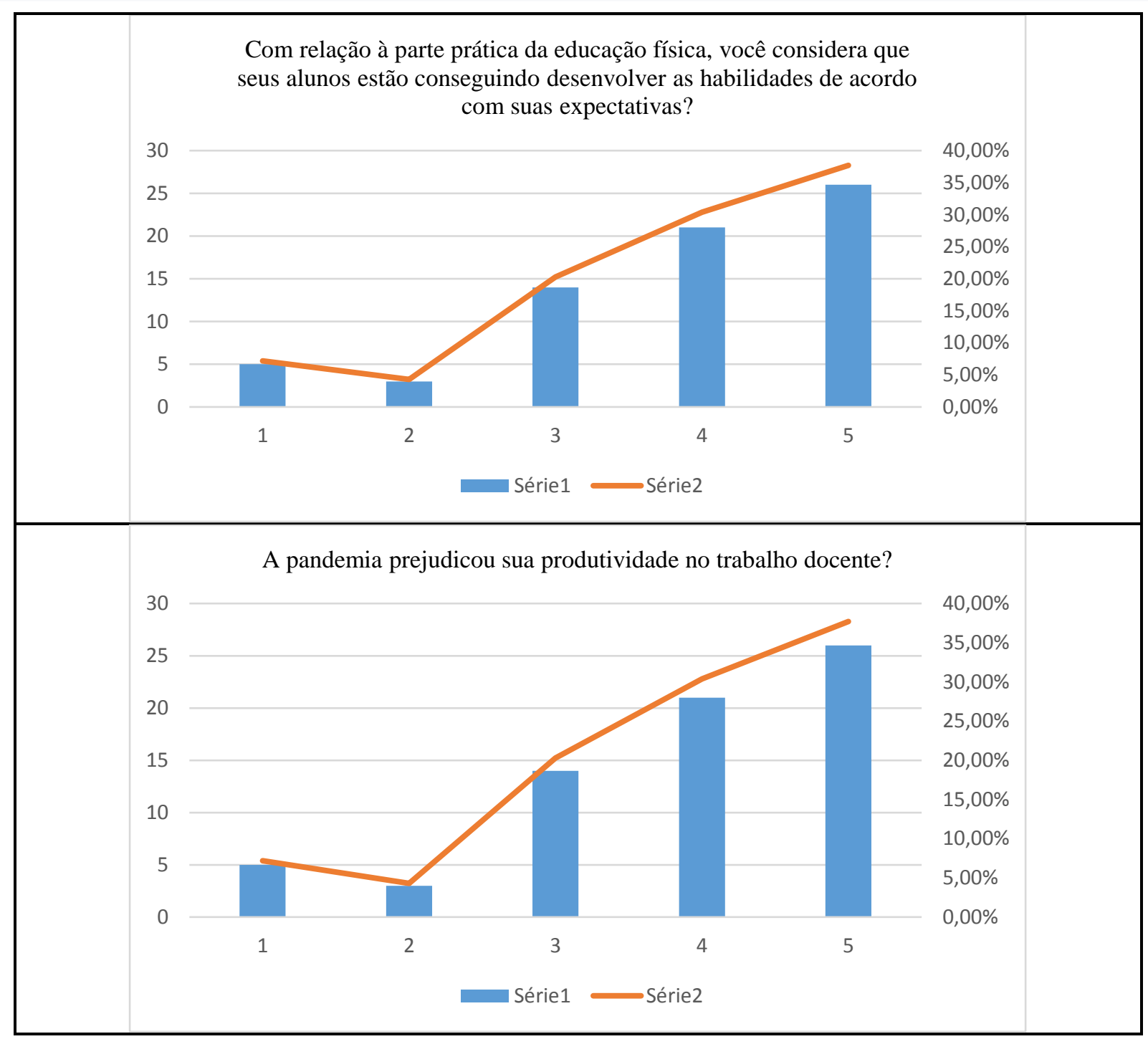

Fonte: Elaboração própria.

Apenas dois professores relataram que não sentem falta de contato social com os alunos. Com relação à percepção sobre o ensino, por meio das ferramentas tecnológicas à distância na educação básica, nesse momento de isolamento social, as respostas foram: $29=$ Moderada, $20=$ Boa, $13=$ Ruim, $4=$ Péssima e 3 = Excelente.

O cenário apresentado no Quadro 5, embora relacione-se com o universo pandêmico que passa o mundo, no Brasil, reflete o sucateamento que sofre a educação, com professores desvalorizados, pouco investimento em formação continuada e o descaso com os cursos de formação docente. 


\section{Análise e discussão dos resultados}

Por meio das respostas dos professores de educação física, obtidas após a aplicação do questionário, pode-se inferir que, em geral, as narrativas docentes sobre as práticas pedagógicas afirmam que existem diversas dificuldades durante período de pandemia. Ademais, englobam aspectos além dos relacionados às próprias práticas pedagógicas, como os aspectos sociais, a saber: distanciamento, convívio e contato social. Tais referências sociais foram citadas frequentemente, o que aponta a necessidade de um trabalho interdisciplinar com outros profissionais, com o intuito de diminuir a probabilidade de danos emocionais à vida dos professores.

Logo, compreende-se que grande parte dos conteúdos do componente curricular educação física aponta a necessidade de contato pessoal entre professores e alunos, apesar disso, esse é um dos principais meios de propagação do vírus. Nada obstante, os principais aprendizados que os professores apresentaram durante a experiência de educação remota reforça a necessidade de apoio didático/ pedagógico da escola, durante período de isolamento social, nomeadamente, no tocante ao uso de novas ferramentas tecnológicas.

Como dito, a principal dificuldade encontrada pelos professores de educação física para a organização e desenvolvimento da sua prática pedagógica está relacionada à desigualdade social enfrentada pelos alunos. Destarte, pode-se acreditar que uma prática pedagógica orientada pode favorecer a sustentação de um processo de ensino e de aprendizagem e o acesso aos conteúdos que poucos alunos têm a oportunidade de vivenciar em tempos de tanta tristeza e medo.

Diante do cenário incerto sobre a vida escolar de milhões de alunos sem aulas presenciais, desde o fechamento das instituições para conter a propagação do novo coronavírus no Brasil, pesquisadores debatem sobre o rumo da educação brasileira durante pandemia de Covid-19.

Silva et al (2020) destacam a importância de reflexões sobre o corpo antes e após a pandemia, especialmente pela volta da militarização dos corpos durante esses tempos de pandemia, tempos tão difíceis, perigosos e duros, de crise e contradições na economia política do capital, de crise sanitária. Destacam, ainda, como o governo brasileiro, aproveitando-se da catástrofe humanitária da pandemia, tenta justificar as profundas mudanças que pretende impor à rede pública de ensino, e que os efeitos deletérios das políticas educacionais durante o período de isolamento social refletem nas práticas concretas dos professores, inclusive os de educação física.

Pesquisadores já se dedicaram a investigar fatores associados às regulações motivacionais para as aulas de educação física, com destaque para a prática adequada e suficiente de atividade física (GUEDES; BERNARDES; YAMAJI, 2020). Por consequência, e considerando o caráter obrigatório nas escolas 
brasileiras, a educação física legitima-se como um componente curricular viável para a promoção da saúde e qualidade de vida dos escolares. Contudo, as experiências didáticas e pedagógicas descritas pelos professores desse componente curricular, durante o período de experiência de educação remota, apresentam-se desmotivadas, em grande parte, identificando que a falta do contato social atualmente é um fator de desmotivação na educação física escolar.

As atividades docentes organizadas durante o desenvolvimento do conteúdo são de suma importância para o processo de ensino-aprendizagem, contanto, o modo como parte dos professores descreve a utilização dos recursos pedagógicos, destacando descontentamento e dificuldades pode comprometer a dimensão incontornável da intervenção educativa nas aulas de Educação Física.

Em outro estudo, Godoi e Borges (2020) deixam evidente que as ações dos professores de educação física estão ancoradas em preocupações e razões de agir no momento da supervisão das práticas dos alunos, as quais expressam, implícita ou explicitamente, concepções de como os estudantes aprendem. No contexto da presente investigação, os mesmos professores que relatam o apoio e disponibilização de recursos das escolas para a continuidade de experiências com os alunos por meio da educação remota, também consideram duvidoso o desenvolvimento das competências e habilidades dos alunos por meio das práticas pedagógicas adotadas, o que, muitas vezes, tem origem na condição social desfavorável dos alunos.

Ao serem questionados sobre o(s) conteúdo(s) do currículo escolar que estavam desenvolvendo durante esse período de isolamento social, notou-se que os professores citaram conteúdos que contemplam a publicação dos Parâmetros Curriculares Nacionais da Educação Física (BRASIL, 1997) e/ ou a Base Nacional Curricular Comum (BNCC, 2018). Tais documentos defendem a cultura corporal de movimento como base do currículo da educação física na escola. Considerando os desafios relatados pelos professores de educação física durante a pandemia, notamos que a educação brasileira precisou readequar-se para manter as aulas dos estudantes. É importante destacar que os critérios adotados pelo Ministério da Educação e as medidas de isolamento e distanciamento social foram realizadas para minimizar a velocidade de propagação da Covid-19.

Sabemos que uma pandemia ocorre devido ao aumento de contágio das doenças e podemos considerar que a globalização é responsável por essas mudanças (FRENK; GÓMEZ- DANTÉS, 2007). A pandemia pode ser responsável pelo estímulo de mecanismos que atuam para combater a doença, regulando, assim, a vida da população. Tais medidas apresentam-se como processos que buscam fazer previsões, estimativas, probabilidades, medições (FOUCAULT, 2008).

Diante do cenário sanitário, transformações metodológicas na educação foram implementadas, tais como as novas tecnologias digitais de informação e comunicação e a modalidade de educação a distância 
(EaD) (MENDONÇA et al, 2013; VIEIRA, 2011), ganhando força na sociedade atual. Calejon e Brito (2020) ressaltam que a escola deve ser um espaço de comunicação e não pode ignorar as inovações que vêm acontecendo frente à pandemia. Com isso, torna-se necessário repensar as experiências vividas e a contribuição que podem oferecer os recursos da tecnologia digital na atividade educativa, bem como refletir sobre as exigências para os professores e as condições de trabalho que lhe são oferecidas.

\section{Considerações finais}

Com este estudo, objetivamos compreender a prática pedagógica do componente curricular educação física, durante período de isolamento imposto pela pandemia de Covid-19, a partir da percepção docente de 69 professores de educação física de Mato Grosso do Sul, atuantes na educação básica durante a pandemia do Covid-19. Deste modo, retomamos o nosso problema: quais as marcas de uma prática pedagógica orientada pela docência em educação física em período de isolamento social durante a pandemia da Covid-19?

Ora, o ceticismo acerca da significação da educação física no contexto escolar, durante a pandemia, pairou sob a academia e a sociedade em geral, uma vez que este componente curricular é caracterizado pela aprendizagem por meio de conteúdos voltados ao "corpo em movimento". Contudo, o momento histórico vivido diante do novo Coronavírus cobra diretamente uma revisão da prática pedagógica docente, ou seja, é necessária uma adequação na intencionalidade educacional do professor de educação física.

Nesse bojo, as marcas de uma prática pedagógica crítica, orientada pela docência em educação física, podem trazer oportunidades didáticas inéditas na história da humanidade, e, em tempos de tantos lutos, pavor, incertezas e desânimos, essas marcas podem oferecer condições para que professores e alunos participem da sociedade de forma reflexiva, questionado "outras possibilidades", e assim, seguir em frente para o futuro.

Os desafios da docência em tempos pandêmicos são inúmeros. A preocupação está em como pensar na docência nesse contexto e nas atividades remotas, nesse caso, especialmente na prática pedagógica do professor de Educação Física. Percebemos a necessidade de conceber práticas em outras perspectivas e aqui, o ineditismo entra em cena e aponta a necessidade da superação de modelos de padronização.

De fato, a luta da sociedade pelo combate ao novo coronavírus marcará os livros de história das próximas gerações, não diferente da forma como os profissionais de educação física estão enfrentando essa crise. Na medida em que a doença causada pelo novo coronavírus se espalha pelo mundo e ameaça o sistema econômico e social, gestores e educadores precisam se concentrar em uma ação: prepararem-se para ensinar 
e apoiar os alunos diante de qualquer dificuldade apresentada e se disporem a enfrentar os possíveis e significativos impactos de longo prazo na educação.

\section{Referências}

BATISTA, C.; MOURA, D. L. Princípios metodológicos para o ensino da educação física escolar: o início de um consenso. Journal of Physical Education, v. 30, 2019.

BRASIL. Ministério da Educação. Base Nacional Comum Curricular. Brasília, 2018.

BRASIL. Ministério da Educação. Parâmetros Curriculares Nacionais. Brasília, DF: MEC/SEF, 1997.

CALEJON, L. M. C.; BRITO, A. S. Entre a pandemia e o pandemônio: uma reflexão no campo da educação. Revista EDUCAmazônia - Educação Sociedade e Meio Ambiente, v, XXV, n. 2, p. 291-311, jul./dez. 2020.

CARLAN, P.; KUNZ, E.; FENSTERSEIFER, P. E. O Esporte como conteúdo da Educação Física Escolar: Estudo de Caso de uma prática pedagógica "inovadora". Movimento (ESEFID/UFRGS), v. 18, n. 4, p. 55-75, set. 2012.

CASSANI, J. M. et al. "We judge the present by the past": the crowning of physical education by sports. Cadernos de Pesquisa, v. 49, n. 173, p. 266-298, 2019.

CASTRO NETA, A. A. A. C. et al. O currículo cultural da Educação Física e os significados das práticas corporais: análise de uma prática pedagógica. Pensar a Prática, v. 23, 2020.

CHEN, N. et al. Epidemiological and clinical characteristics of 99 cases of 2019 novel coronavirus pneumonia in Wuhan, China: a descriptive study. The Lancet, v. 395, p. 507-513, 2020.

FARIAS, H. S. F. O avanço da Covid-19 e o isolamento social como estratégia para redução da vulnerabilidade. Espaço e Economia. Revista Brasileira de Geografia Econômica, v. 17, 2020.

FRANCO, M. A. Prática pedagógica e docência: um olhar a partir da epistemologia do conceito. Revista Brasileira de Estudos Pedagógicos, v. 97, n. 247, p. 534-551, 2016.

FOUCAULT, M. Em defesa da sociedade. São Paulo: Martins Fontes, 2008.

FRENK, J.; GÓMEZ-DANTÉS, O. Globalização e saúde: desafios para os sistemas de saúde em um mundo interdependente. [s. 1.: s. n.], 2006-2007.

GODOI, M.; BORGES, C. A supervisão das práticas dos estudantes pelos professores de Educação Física. Motrivivência, v. 32, n. 62, p. 1-21, 2020.

GUEDES, D. P.; BERNARDES, A. G.; YAMAJI, B. H. S. PLOC - Regulações motivacionais para aulas de Educação Física. Revista Brasileira de Educação Física e Esporte, v. 34, n. 1, p. 19-31, 2020. 
HANDCOCK, M. S.; GILE, K. J. On the concept of snowball sampling. Sociological Methodology, v.41, n. 1, p. 367-371, ago. 2011.

LIMENA, M. M. C.; RODRIGUES, M. L. Metodologias multidimensionais em ciências humanas. Brasília: Liber Livro, 2006.

MENDONÇA, J. R. C. et al. Competências eletrônicas de professores para educação a distância no ensino superior no brasil: discussão e proposição de modelo de análise. Recife: Universidade Federal de Pernambuco, 2013.

MILISTETD, M. et al. Formação de treinadores esportivos: orientações para a organização das práticas pedagógicas como componente curricular. Journal of Physical Education, v. 28, n. 1, p. 2849-2849, 16 ago. 2017.

MINAYO, M. C. S. O desafio do conhecimento: pesquisa qualitativa em saúde. 4. ed. São Paulo/Rio de Janeiro: Hucitec/Abrasco, 2004.

MINISTÉRIO DA SAÚDE. Coronavírus (Covid-19). Brasília, DF, 2020. Disponível em: https://coronavirus.saude.gov.br/sobre-a-doenca\#o-que-e-covid. Acesso em: 10 maio 2020.

MOTA, A. R.; ROSA, C. T. W. da. Ensaio sobre metodologias ativas: reflexões e propostas. Revista Espaço Pedagógico, v. 25, n. 2, p. 261-276, 2018.

OLIVEIRA, R. C.; DAOLIO, J. Na "periferia" da quadra: Educação Física, cultura e sociabilidade na escola. Pro-Posições, v. 25, n. 2, p. 237-254, 2014.

PIRES, R. R. C. Os efeitos sobre grupos sociais e territórios vulnerabilizados das medidas de enfrentamento à crise sanitária da covid-19: propostas para o aperfeiçoamento da ação pública: nota Técnica. Brasília, DF: IPEA, 2020. Disponível em: http://www.ipea.gov.br/portal/index.php?option=com_alphacontent\&view=alphacontent\&Itemid=357.

Acesso em: 10 maio 2020.

SANTANA FILHO, M. M. Educação geográfica, docência e o contexto da pandemia COVID-19. Rev. Tamoios, v.16 n.1, 2020.

SANTOS, W. dos; PAULA, S. C. DE; STIEG, R. Avaliações institucionais e de sistemas na formação de professores em Educação Física na América Latina. Revista Espaço Pedagógico, v. 26, n. 1, p. 99-116, 2019.

SILVA, M. R. da et al. Bolsonaro e a COVID-19: e daí? "o Brazil tá matando o Brasil”, "do Brasil, SOS ao Brasil”, “chora a nossa pátria, mãe gentil...”. Motrivivência, v. 32, n. 62, p. 1-19, 2020.

SILVA, S. P. da. Educação e Justiça Social na Contemporaneidade: repensando o sentido da docência no âmbito escolar. Revista Espaço Pedagógico, v. 26, n. 3, p. 676-700, 2019.

THOMAS, J. R.; NELSON, J. K.; SILVERMAN, S. J. Método de pesquisa em atividade física. 6. ed. Porto Alegre: Artmed, 2012. 
VIEIRA, R. S. O papel das tecnologias da informação e comunicação informação e comunicação na educação a distância: um estudo sobre a percepção do professor/tutor. Revista Brasileira de Aprendizagem Aberta e a Distância, São Paulo, v. 10, p. 68-70, 2011.

WORLD HEALTH ORGANISATION (WHO). Rolling updates on coronavirus disease (COVID-19). 2020. Disponível em: https://www.who.int/emergencies/diseases/novel- coronavirus 2019/events-as-theyhappen. Acesso em: 10 maio 2020.

\section{Como citar este artigo}

ZAIM-DE-MELO, R.; RIZZO, D. T.S.; RIBEIRO, E. A. G. Prática pedagógica e docência: o olhar do professor de educação física no enfrentamento da Covid-19. Revista Kinesis, Santa Maria, v. 39, p.0117, 2021.

* O presente trabalho não contou com apoio financeiro de nenhuma natureza para sua realização. 